\title{
Lethal effects and mechanism of infrared radiation on Sitophilus zeamais and Tribolium castaneum in rough rice
}

\author{
Chao Ding ', Yongsheng Pei', Tingting Tao², Guofeng Yang', Yan Wang', Wei Yan', Xiaolong \\ Shao' \\ ${ }^{1}$ College of Food Science and Engineering/Collaborative Innovation Center for Modern Grain Circulation and \\ Safety/Key Laboratory of Grains and Oils Quality Control and Processing, Nanjing University of Finance and \\ Economies, \\ ${ }^{2}$ Institute of Food Safety and Nutrition, Jiangsu Academy of Agricultural Sciences, Nanjing 210014, China \\ ${ }^{3}$ Wenyuan road, Nanjing, Jiangsu 210023, China \\ *Corresponding author: cding@nufe.edu.cn \\ DOI 10.5073/jka.2018.463.108
}

\begin{abstract}
The objective of this study was to investigate the characteristics of adult Sitophilus zeamais and Tribolium castaneum, and the $21.1 \%$ dry base (d.b.) MC of rough rice by ATR-FTIR spectra, and determine the theoretical optimum infrared (IR) heating temperature of the tested samples. In laboratory experiments, a ceramic IR drying device was used to heat infested rough rice to research the mortality of Sitophilus zeamais and Tribolium castaneum, the drying characteristics of rough rice, and milling quality. The theoretical calculation optimum temperature of IR heating was $300{ }^{\circ} \mathrm{C}$ according to the results of FTIR spectra. In addition, the effects of the different IR radiation intensities and heated rough rice temperatures on mortality of insects, moisture removal, and milling quality were determined in this text. A high insect mortality, heating rate and corresponding high moisture removal were achieved by using IR heating. After heating, tempering process significantly increased insect mortality when the heated tempered rice temperature was less than $55^{\circ} \mathrm{C}$, and improve moisture removal and milling quality of rough rice during nature air cooling. When the rice heated under the IR radiation intensity of $2780 \mathrm{~W} / \mathrm{m}^{2}$ for $110 \mathrm{~s}$, the rice temperature reached $60.2^{\circ} \pm 0.5^{\circ} \mathrm{C}, 100 \%$ mortality of S. zeamais and T. castaneum, and 3.97 percentage points of moisture removal during the heating period after tempering and natural cooling. In addition, the high rice milling quality can be achieved after tempering treatment. Therefore, it can be concluded that the optimum conditions of simultaneous disinfestation and drying were $60{ }^{\circ} \mathrm{C}$ rice temperature under the IR radiation intensity of $2780 \mathrm{~W} / \mathrm{m}^{2}$, followed by tempering and natural cooling.
\end{abstract}

Keywords rough rice; infrared radiation; Sitophilus zeamais; Tribolium castaneum; disinfestation; milling quality

\section{Introduction}

Rough rice is a major source of food for both human and animals as one of the three main grain varieties. During storage, infestations by stored grain pests may occur if the internal and external conditions are suitable (Lee et al., 2001). It was estimated that $10-40 \%$ of worldwide annual production of grain (Mishra et al., 2013) and 27\% of the milled rice was lost due to the infestation of pests (Alfonso-Rubí et al., 2003). Various methods of pests control have been implemented to protect the rough rice, in which the chemical fumigation is the most widely used method for disinfestation (Ogendo et al., 2010). However, the effect of chemical fumigation is becoming less effective due to the increase of resistance of insect pests. Chemical application may affect the environment and grain, which could potentially affect the health of human beings (Vadivambal, et al., 2010). Therefore, it is urgent to research and develop alternative technology to chemical fumigation methods.

Infrared radiation (IR) is an efficient and safe physical process method, with wavelengths range from 0.75 to $100 \mu \mathrm{m}$. IR can be directly transferred to the material without medium, and converted into heat after the absorption of the electromagnetic wave. In the 1940s, gas-fired IR technology was firstly used for grain disinfestation. Frost et al. discovered that the mortality rate increased with the temperature rise of insect pests (Frost et al., 1944). In the 1960s to 1980s, gas-fired IR method began to be investigated to kill different immature stages and adults of stored-grain pests (Cogburn 1967; Cogburn et al., 1971; Kirkpatrick and Tilton, 1972b; Tilton et al., 1983). Tilton et al. (1963) exposed three species of insects commonly found in grain to IR and achieved $100 \%$ of mortality with the temperature of grain ranging from $65^{\circ} \mathrm{C}$ to $70{ }^{\circ} \mathrm{C}$. It was also reported that adult Rhyzopertha dominica was killed by IR at $57^{\circ} \mathrm{C}$ (Kirkpatrick et al., 1972a). The infrared generators in the above 
study had an open flame with temperatures exceeding $926^{\circ} \mathrm{C}$ (Kirkpatrick and Cagle, 1978). Such high temperatures are not suitable for grain processing because of potential safety hazard. In recent years, a sort of flameless catalytic infrared technology was developed for various drying applications, and these catalytic emitters generated temperatures of less than $500^{\circ} \mathrm{C}$. Khamis et al. (2010) treated Rhyzopertha dominica, Sitophilus oryzae and Tribolium castaneum by the flameless catalytic infrared, and proved that there was significant correlation between mortality and temperatures of the 3 pests according to logistic regression statistics. Pan et al. (2008) concluded that rough rice was heated to $60{ }^{\circ} \mathrm{C}$ followed by tempering and slow cooling can achieve simultaneous drying and disinfestation with high rice milling quality. However, the effects of different IR intensity on the mortality of insects and its theoretical mechanism of insect lethality were unclear. Therefore, the objectives of this research was to investigate the effect of IR on rice disinfestation and rice quality, and analyze the differences of rice and insect heating rate to reveal the relevant mechanism.

\section{Materials and methods}

Preparation of insect and rough rice samples

As one of the main cultivated japonica rice in Jiangsu province, freshly harvested No.5 Huaiyin japonica rough rice was selected for this study, which was obtained from Shibuqiao Grain Reserve Depot, Nanjing, Jiangsu province. The moisture content of rough rice was $21.1 \pm 0.5 \%$ in dry basis (d.b.). All moisture content was determined by the standard air oven method at $130 \pm 2{ }^{\circ} \mathrm{C}$ for $24 \mathrm{~h}$ (ASAE, 1995) in an electric dry oven (Model 101-3AS, Sujin Instrument Factory, Shang Hai, China) and was expressed as percentage in dry mass basis with triplicates.

Two major stored-grain insects, Tribolium castaneum and Sitophilus zeamais obtained from Chengdu Grain Storage Research Institute, Chengdu, Sichuan province, were used for the study. The T. castaneum samples were grown in laboratory on wheatmeal and yeast extract (Oxoid Lid, Wade Road, Basingstoke, Hants, UK) and maintained at $28 \pm 2{ }^{\circ} \mathrm{C}$ and a relative humidity (RH) of $64 \pm 3 \%$ (Kirkpatrick 1975). The S. zeamais was maintained on organic whole wheat (Beidahuang Qinmin Organic Foods CO., LTD) in incubator at a temperature of $30 \pm 2{ }^{\circ} \mathrm{C}$ and a $\mathrm{RH}$ of $70 \pm 2 \%$.

\section{ATR-FTIR spectra of insects and rough rice}

IR heating results in the vibration and rotation of atoms and molecules and leads to a rise in sample temperature. In order to research the IR absorption characteristics of insect and rough rice, the spectral information of live adults and rough rice were collected by attenuated total reflectanceFourier transform infrared spectroscopy (ATR-FTIR) (Tensor 27, Bruker Corporation, Germany). A single adult or rough rice kernel was placed at the center of the ATR ZnSe crystal (Pike, USA) using a pair of forceps. The background spectrum of the air was scanned before determination of the sample. Through ATR-FTIR application, the spectral region of sample ranged from 4000 to $600 \mathrm{~cm}^{-1}$ The number of scans was 64 , and the resolution was $4 \mathrm{~cm}^{-1}$. All reported data were means of triplicates. The results of samples exposed to ATR-FTIR spectra were calculated to evaluate the optimum radiation temperature during IR heating following Wien displacement law with equation (1).

$$
\mathrm{T}=2898 / \lambda_{\max }
$$

Where T is blackbody temperature, $\mathrm{K} . \lambda_{\max }$ is the peak wavelength of blackbody radiation energy.

Infrared heating treatment

A laboratory-scale ceramic infrared drying device provided by Maybo Innovation (MB-EHR12/10KW, Zhen Jiang) was used to treat the rough rice and insect samples. The infrared drying device consists of an IR emitter, a circulating fan, a sample holder and a control panel. The IR emitter was the source of IR radiation (HTS, Elstein-Werk, Germany), and it had a surface temperature of about $630^{\circ} \mathrm{C}$ and 
corresponding peak wavelength of $3.2 \mu \mathrm{m}$, assuming a blackbody. The sample holder was a steel reticulation of dimension $50 \mathrm{~cm} \times 35 \mathrm{~cm}$.

The samples, made up of a mixture of rough rice and insects were placed in a single layer on a tray with a loading rate of $2.08 \mathrm{~kg} / \mathrm{m}^{3}$ at a $20 \mathrm{~cm}$ distance under the IR emitter. The mixture samples were separately heated to $50,55,60$ and $65^{\circ} \mathrm{C}$ under different IR emitter temperatures $(200,300,400$, and $500{ }^{\circ} \mathrm{C}$ ), which corresponds to the IR radiation intensity of $2125,2780,3358$ and $3974 \mathrm{~W} / \mathrm{m}^{2}$. The temperature of IR emitter was controlled using the control panel. The radiation intensity of heated rice was measured with Ophir thermal excimer absorber head (FL205A, Ophir, Washington, USA) under the different temperature of IR emitter. The temperature of heated rice was measured by using a type-K thermocouple (RDXL4SD, OMEGA Engineering Inc. Stamford, USA), which can be monitored in real time by contact of the thermocouple to the rough rice. The experiments were implemented using rough rice samples and insects with a proportion of 50 insects $/ 100 \mathrm{~g}$ rough rice (Yan et al., 2014). The single layer of infested rough rice was uniformly distributed on the holder, insects were randomly distributed.

Long period of IR heating without tempering would affect milling quality of rough rice due to the high heating rate of rice (Ding et al., 2015a). To improve the rice milling quality, treated rough rice was immediately transferred into sealed containers and placed in an incubator with the same temperature of heated rice for 4 hours (Khir et al., 2011). The tempered and non-tempered samples were prepared for analyzing the influences of tempering on disinfestation and milling quality. After the tempering or no-tempering treatment, the samples were placed on a laboratory bench for 40 mins of natural cooling to room temperature of $23 \pm 1^{\circ} \mathrm{C}$.

\section{Determination of temperature distribution of infested rough rice}

Water molecules are highly polar and easily absorb the radiation energy into heat. The moisture content of insects is much higher than that of rough rice, and results in the heating rate of insects higher than that of rough rice under IR treatment. In order to analyze the temperature distribution of rough rice and insects, a series of temperature monitoring experiments were conducted. Based on the theoretical calculation optimum temperature of IR heating was $300^{\circ} \mathrm{C}$. This is according to the results of FTIR spectra, and the spectra of adult S. zeamais and T. castaneum were similar. Thus, the adult $T$. castaneum samples were placed in the circular area uniformly in a thin layer ( $3 \mathrm{~mm}$ thick). The mixture of rough rice and adult $T$. castaneum were placed in single layer on tray at a $20 \mathrm{~cm}$ distance under IR emitter, and were separately heated under the IR emitter radiation intensity of $2780 \mathrm{~W} / \mathrm{m}^{2}$ for $160 \mathrm{~s}$. After IR heating, the temperatures distribution photographs of heated rice and insects were captured by infrared thermal imager (TiX580, Fluke Corporation. USA). The image results could be analyzed and processed by its own software (FLUKE SmartView 3.7).

During the IR heating experiments, the insects number were much lower than rough rice and they tend to move to the bottom of rice layer, resulting in the temperature determination of insects difficultly. To determine the temperature distribution of insects by IR heating, the heated insects were concentrated in a circle area without rice samples, and the radius of the circle area was about $3 \mathrm{~cm}$.

\section{Assessment of mortality of Sitophilus zeamais and Tribolium castaneum}

Treated rough rice samples were placed in jars and placed in incubator at $28^{\circ} \mathrm{C}$ and $70 \% \mathrm{RH}$ to allow development of any surviving S. zeamais and T. castaneum. Adult mortality was determined after 24 h. Mortality of eggs, larvae and pupae was based on the number of adults that emerged from those stages (Khamis et al., 2010). The values were compared with adult emergence in untreated rough rice samples. 
Determination of rice milling quality

Milling quality is is an important factor for the processing and sale of rice, the most important rice milling quality indices are total rice yield (TRY) and head rice yield (HRY). To evaluate the effects of IR heating treatment, the $400 \mathrm{~g}$ rice samples were dehulled and milled using Yamamoto Husker (FC2K) and Yamamoto Rice Mill (VP-222N, Yamamoto Co. Ltd., Japan). The rice samples were milled three times to achieve well-milled rice as defined by the standard GB 1350-2009. The settings of throughput and whitening were 1 and 4 during the first two millings and 1 and 5 during the third milling process (Ding et al., 2015b; Pan et al., 2007). TRY was the percentage of milled rice weight divided by the weight of untreated rough rice (GB/T 5495-2008). HRY was determined by GB/T 21719-2008. All reported data of milling quality indicators are means of triplicates.

\section{Statistical analysis}

Analysis of variance (ANOVA) was performed in a completely randomized design, data of the mortality of insects and rice milling quality were statistically analyzed with PASW 18 (IBM SPSS Statistics, Chicago, IL, USA) at a $95 \%$ confidence level. One-way ANOVA with Duncan's multiple comparisons test were applied to compare the data among different radiation intensity and different exposed time. Significance was reported at $p<0.05$ for all data.

\section{Results and Discussion}

Characteristics of the ATR spectra of insects and rough rice

The average ATR-FTIR spectra of adult S. zeamais, T. castaneum, and rough rice as shown in Fig. 1. The spectra form of adult S. zeamais and T. castaneum were similar. There are two significant absorption region of adult S. zeamais and T. castaneum, that was mainly distributed in the wavenumber range of $3600-3000$ and $1800-800 \mathrm{~cm}^{-1}$. The rough rice has a similar significant absorption in the wavenumber range of $3600-3000 \mathrm{~cm}^{-1}$. The spectrum of the rough rice also has a higher absorption in the wavenumber range of $1250-800$ and $1700-600 \mathrm{~cm}^{-1}$, which was different from the fingerprint region in $1800-800 \mathrm{~cm}^{-1}$ of the $S$. zeamais and $T$. castaneum. Since the insects consist of higher amount of proteins and lipids than rough rice that mainly absorb the IR with wavelength ranges from 5.71 to $10 \mu \mathrm{m}$ (corresponding wavenumber were 1751 to $1000 \mathrm{~cm}^{-1}$ ) (Pan and Atungulu, 2011). Therefore, the spectra of adult S. zeamais and T. castaneum could absorb higher IR within 1800-800 $\mathrm{cm}^{-1}$.

The absorption peak around $3600-3000 \mathrm{~cm}^{-1}$ is related to vibration of $\mathrm{O}-\mathrm{H}$, with the relevant component of O-H being water and/or carbohydrates in the samples (lonel 1992). The maximum absorbance of adult S. zeamais and T. castaneum in this range was 0.23 and 0.16 , which are higher than that of the rough rice (0.05). This is may be due to the higher MC of adult S. zeamais and T. castaneum than that of the rough rice. The corresponding temperature of the spectra region were range from $869^{\circ} \mathrm{C}$ to $1043^{\circ} \mathrm{C}$ according Wien displacement law, and this is too high for large-scale commercial processes.

The maximum IR absorbances of adult S. zeamais and T. castaneum were 0.2 and 0.3 at $1632 \mathrm{~cm}^{-1}$, and were significantly higher than that of rough rice $\left(0.15\right.$ at $\left.1020 \mathrm{~cm}^{-1}\right)$. Obviously, the IR absorption ability of insects is higher than that of rough rice. To improve the efficiency of IR drying and disinfestation, the strong absorption wavelength range should be applied during IR treatment. According Wien displacement law, the corresponding temperature of the wavenumber of $1800 \mathrm{~cm}^{-}$ ${ }^{1}$ was $248^{\circ} \mathrm{C}$. As practical materials, the IR absorption rate of S. zeamais, T. castaneum and rough rice were less than that of blackbody. To facilitate the experiment operation and commercial process requirements, the IR radiation temperature of $300{ }^{\circ} \mathrm{C}$ should be more effective with low energy consumption. 


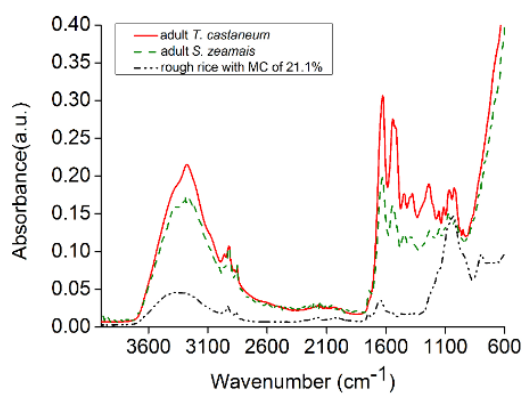

Fig. 1 Average attenuated total reflectance-Fourier transform infrared (ATR-FTIR) spectra of adult S. zeamais, T. castaneum and rough rice with MC of $21.1 \%$.

Mortality of insects

Mortality of Sitophilus zeamais

The mortality of egg, larvae, pupae, and adult stages of S. zeamais is given in table 1 . The control mortality of the four stages of $S$. zeamais was zero. After the rice samples were heated to temperatures of $50,55,60$ and $65^{\circ} \mathrm{C}$, the mortality of adult $S$. zeamais was $81 \pm 4.6,98 \pm 3.5,99 \pm 0.6$ and $100 \%$ at the radiation intensity of $2125 \mathrm{~W} / \mathrm{m}^{2}$ with non-tempering treatment, respectively. The mortality of S. zeamais was positively correlated with the heated rice temperature, and above $96 \%$ when the rough rice temperature exceeded $55^{\circ} \mathrm{C}$.

After the rough rice temperature heated to $50{ }^{\circ} \mathrm{C}$, regardless of tempering, the four stages of $S$. zeamais were still living. The results revealed $S$. zeamais could not reach the complete death when the rough rice temperature heated to $50^{\circ} \mathrm{C}$ in a short time (110 s). However, the mortality of adult $S$. zeamais at the radiation intensity of $2125,2780,3358$ and $3974 \mathrm{~W} / \mathrm{m}^{2}$ was $81 \pm 2.6,76 \pm 3.5,73 \pm 3.5$, and $93 \pm 3.1 \%$ when the rough rice temperature of $50{ }^{\circ} \mathrm{C}$ without tempering, respectively. Only $7 \pm 3.1 \%$ adult S. zeamais survived at the radiation intensity of $3974 \mathrm{~W} / \mathrm{m}^{2}$ without tempering treatment. Similar ascend trends of the mortality of four stages of S. zeamais were observed along with the increase of IR intensity at same heated rough rice temperature. The S. zeamais temperature rose faster at higher radiation intensity, and the temperature of $S$. zeamais increased rapidly in a short time, which could result in dramatic changes in S. zeamais. It was also shown that the mortality of adult S. zeamais was lower than that of other stages at the same experimental condition when the heated rice temperature was $50{ }^{\circ} \mathrm{C}$ without tempering treatment. For example, the mortality of S. zeamais egg, larvae, pupae, and adult stages was $87 \pm 4.6,83 \pm 4.0,81 \pm 4.5$ and $76 \pm 3.5 \%$ at the radiation intensity of $2780 \mathrm{~W} / \mathrm{m}^{2}$ and the heated rice temperature of $50{ }^{\circ} \mathrm{C}$ without tempering treatment, respectively. This might be due to the fact that the adults move to the lower temperature area when heated by IR.

The mortality of all life stages of S. zeamais was $100 \%$ when the rough rice was heated to $65{ }^{\circ} \mathrm{C}$, regardless of tempering, and $55{ }^{\circ} \mathrm{C}$ with tempered rice that achieved $100 \%$ mortality. The results obtained agreed with reported results that the time to mortality of the insect was less than $40 \mathrm{~s}$ when they heated to temperature above $65^{\circ} \mathrm{C}$ (Kirkpatrick and Tilton, 1972b). In addition, the nontempered samples, especially at low rice temperature, had fewer insects survived than the samples with tempering. This could be because the lethal temperature of S. zeamais was about $56{ }^{\circ} \mathrm{C}$ (Schroeder and Tilton, 1961), the lethal rate would significantly increase when S.zeamais for a long time $(4 \mathrm{~h})$ at the rough rice temperature beyond $50{ }^{\circ} \mathrm{C}$.

Mortality of Tribolium castaneum

The mortality of egg, larvae, pupae, and adult stages of $T$. castaneum is given in table 2 . The control mortality for the four stages of $T$. castaneum was zero. There are many similarities to the results of $S$. 
zeamais mortality. For instance, the mortality of $T$. castaneum adult is the lowest among the four stages. In addition, at the $65{ }^{\circ} \mathrm{C}$ of the rice temperature, regardless of tempering, $100 \%$ mortality were found in all the samples under such treatment. Moreover, tempering treatment could effectively improve the mortality of insect. However, the mortality of egg, larvae, pupae, and adult stages of T. castaneum was $75 \pm 2.1,73 \pm 2.6,64 \pm 3.2$ and $56 \pm 2.1 \%$ at the rice temperature of $50{ }^{\circ} \mathrm{C}$ without tempering, respectively, which was lower than that of four stages of S. zeamais (by $87 \pm 4.6$, $83 \pm 4.0,81 \pm 4.5$ and $76 \pm 3.5 \%$ ) at the same treatment conditions. The results were especially obvious when heated rice temperatures were 50 and $55^{\circ} \mathrm{C}$. This shows that $T$. castaneum has a stronger heat resistance than S. zeamais at these temperatures. In addition, $100 \%$ mortality was observed in all samples for the four stages of $T$. castaneum, at rice temperatures of $60^{\circ} \mathrm{C}$.

Based on these results, it can be concluded that insects tested can be effectively killed by using IR, especially with the tempering treatment. It is recommended that the rice temperature of IR heating be controlled at close to $60^{\circ} \mathrm{C}$, and followed tempering treatment, which could ensure that the mortality of S. zeamais and T. castaneum was $100 \%$.

Temperature distribution of rough rice and insects

The rough rice sample temperatures changes during different heating durations under different radiation intensities were shown in Fig. 2. It was proposed that the heated rice temperature of $60^{\circ} \mathrm{C}$ was the suitable drying parameter of IR drying for rough rice (Ding et al., 2015b). In this research, after $30 \mathrm{~s}$ of IR heating with intensity of $3974 \mathrm{~W} / \mathrm{m}^{2}$, the temperature of the single layer of rice samples with $M C$ of $21.1 \pm 0.5 \%$ achieved $60.5 \pm 1.8^{\circ} \mathrm{C}$. For the IR intensity of 2125,2780 and 3358 $\mathrm{W} / \mathrm{m}^{2}$, the rice temperatures increased to $10.7+23.2{ }^{\circ} \mathrm{C}, 20.5+23.2{ }^{\circ} \mathrm{C}$ and $39.0+32.2{ }^{\circ} \mathrm{C}$ after $60 \mathrm{~s}$ of heating, respectively. It was obvious that the IR heating could rapidly increase the rice temperature. Because IR is an electromagnetic wave with wavelength of 0.75 to $1000 \mu \mathrm{m}$ (Carlomagno et al., 2002). When the infrared electromagnetic wave acts on the rice surface, the electric, vibrational, and rotational states of atoms and molecules in rice will be changed accordingly, and the IR energy absorbed by rice will be transformed into thermal motion of molecules allowing rice to heat and evaporate the water for drying (Matsuoka 2011).

Under the same loading capacity and thickness of rough rice, when the radiation intensity was 2125 $\mathrm{W} / \mathrm{m}^{2}$, the temperature rough rice temperature rose to $60^{\circ} \mathrm{C}$ after $260 \mathrm{~s}$ exposed time. In general, the rough rice temperature was linear with the exposed time, it means that the average heating rate of rough rice was $0.14^{\circ} \mathrm{C} / \mathrm{s}$. Similarly, under the radiation intensity was 2780 and $3358 \mathrm{~W} / \mathrm{m}^{2}$, the temperature rose to $60^{\circ} \mathrm{C}$ after $110 \mathrm{~s}$ and $60 \mathrm{~s}$ exposed time, and the corresponding average heating rate of rough rice was $0.34^{\circ} \mathrm{C} / \mathrm{s}$ and $0.62^{\circ} \mathrm{C} / \mathrm{s}$. The results revealed that the heating rate of rough rice and radiation intensity is positively correlated, and suggests that IR intensities may achieve a higher heating rate for rough rice. This is because that the higher energy could cause stronger vibration of molecules in rough rice, which leading to faster heating rate of rough rice. However, when the radiation intensity was $3974 \mathrm{~W} / \mathrm{m}^{2}$, the temperature of rough rice was $72.3 \pm 1.3^{\circ} \mathrm{C}$ after $40 \mathrm{~s}$ of heating, and the average heating rate of rough rice was $1.23^{\circ} \mathrm{C} / \mathrm{s}$, the heating rate of rough rice was high and easily cause gelatinization and denaturation of rough rice starch and protein, even lead to the burning of heated rough rice. Therefore, in order to avoid the harm of high IR radiation intensity and improve heating efficiency for commercial drying processing of rough rice, the radiation intensity of 2780 and $3358 \mathrm{~W} / \mathrm{m}^{2}$ were more operable and reasonable among the four radiation intensities.

Table 1 Mortality of life stages (egg, larvae, pupae, adult) of S. zeamais expose to IR radiation intensity of 2125, 2780,3358 and $3974 \mathrm{~W} / \mathrm{m}^{2}$ with or without tempering. 
Data (mean $\pm S D$ ) in each column with different letters have significant differences $(p<0.05)$.

\begin{tabular}{|c|c|c|c|c|c|c|}
\hline \multirow{2}{*}{$\begin{array}{c}\text { Radiation } \\
\text { intensity }\left(\mathrm{W} / \mathrm{m}^{2}\right)\end{array}$} & \multirow{2}{*}{$\begin{array}{l}\text { Rice temperature } \\
\left({ }^{\circ} \mathrm{C}\right)\end{array}$} & \multirow{2}{*}{ Tempering } & \multicolumn{4}{|c|}{ Mortality of different life stages of S. zeamais (\%) } \\
\hline & & & egg & larvae & pupae & adult \\
\hline \multirow[t]{8}{*}{2125} & 50 & Yes & $94 \pm 2.5 a c$ & $95 \pm 2.0 \mathrm{a}$ & $92 \pm 2.3 a$ & $92 \pm 4.5 a$ \\
\hline & 50 & No & $88 \pm 3.2 b$ & $86 \pm 3.2 b$ & $82 \pm 2.6 b$ & $81 \pm 4.6 b$ \\
\hline & 55 & Yes & $100 d$ & $100 \mathrm{e}$ & $100 d$ & $100 c$ \\
\hline & 55 & No & $100 d$ & $100 \mathrm{e}$ & $100 d$ & $98 \pm 3.5 c$ \\
\hline & 60 & Yes & $100 d$ & $100 \mathrm{e}$ & $100 d$ & $100 c$ \\
\hline & 60 & No & $100 d$ & $100 \mathrm{e}$ & $100 d$ & $99 \pm 0.6 c$ \\
\hline & 65 & Yes & $100 d$ & $100 \mathrm{e}$ & $100 d$ & $100 c$ \\
\hline & 65 & No & $100 d$ & $100 \mathrm{e}$ & $100 d$ & $100 c$ \\
\hline \multirow[t]{8}{*}{2780} & 50 & Yes & $93 \pm 2.6 a$ & $91 \pm 3.8 c$ & $88 \pm 2.3 c$ & $83 \pm 4.6 b$ \\
\hline & 50 & No & $87 \pm 4.4 b$ & $83 \pm 4.0 d$ & $81 \pm 4.5 b$ & $76 \pm 3.5 d$ \\
\hline & 55 & Yes & $100 d$ & $100 \mathrm{e}$ & $100 d$ & $100 c$ \\
\hline & 55 & No & $100 d$ & $100 \mathrm{e}$ & $99 \pm 0.6 d$ & $98 \pm 2.5 c$ \\
\hline & 60 & Yes & $100 d$ & $100 \mathrm{e}$ & $100 d$ & $100 c$ \\
\hline & 60 & No & $100 d$ & $100 \mathrm{e}$ & $100 d$ & $99 \pm 1.5 c$ \\
\hline & 65 & Yes & $100 d$ & $100 \mathrm{e}$ & $100 d$ & $100 c$ \\
\hline & 65 & No & $100 d$ & $100 \mathrm{e}$ & $100 d$ & $100 c$ \\
\hline \multirow[t]{8}{*}{3358} & 50 & Yes & $96 \pm 2.1 c$ & $94 \pm 3.6 a$ & $89 \pm 2.6 c$ & $82 \pm 3.2 b$ \\
\hline & 50 & No & $87 \pm 3.0 b$ & $85 \pm 3.1 \mathrm{bd}$ & $78 \pm 2.1 \mathrm{e}$ & $73 \pm 3.5 d$ \\
\hline & 55 & Yes & $100 d$ & $100 \mathrm{e}$ & $100 d$ & $100 c$ \\
\hline & 55 & No & $100 d$ & $100 \mathrm{e}$ & $100 d$ & $96 \pm 2.9 c$ \\
\hline & 60 & Yes & $100 d$ & $100 \mathrm{e}$ & $100 d$ & $100 c$ \\
\hline & 60 & No & $100 d$ & $100 \mathrm{e}$ & $100 d$ & $100 c$ \\
\hline & 65 & Yes & $100 d$ & $100 \mathrm{e}$ & $100 d$ & $100 c$ \\
\hline & 65 & No & $100 d$ & $100 \mathrm{e}$ & $100 d$ & $100 c$ \\
\hline \multirow[t]{8}{*}{3974} & 50 & Yes & $100 d$ & $100 \mathrm{e}$ & $100 d$ & $100 c$ \\
\hline & 50 & No & $100 d$ & $100 \mathrm{e}$ & $95 \pm 1.2 f$ & $93 \pm 3.1 a$ \\
\hline & 55 & Yes & $100 d$ & $100 \mathrm{e}$ & $100 d$ & $100 c$ \\
\hline & 55 & No & $100 d$ & $100 \mathrm{e}$ & $100 d$ & $98 \pm 2.6 c$ \\
\hline & 60 & Yes & $100 d$ & $100 \mathrm{e}$ & $100 d$ & $100 c$ \\
\hline & 60 & No & $100 d$ & $100 \mathrm{e}$ & $100 d$ & $100 c$ \\
\hline & 65 & Yes & $100 d$ & $100 \mathrm{e}$ & $100 d$ & $100 c$ \\
\hline & 65 & No & $100 d$ & $100 \mathrm{e}$ & $100 d$ & $100 c$ \\
\hline
\end{tabular}


Table 2 Mortality of life stages (egg, larvae, pupae, adult) of T. castaneum expose to IR radiation intensity of $2125,2780,3358$ and $3974 \mathrm{~W} / \mathrm{m}^{2}$ with or without tempering.

\begin{tabular}{|c|c|c|c|c|c|c|}
\hline \multirow{2}{*}{$\begin{array}{l}\text { Radiation } \\
\text { intensity }\left(\mathrm{W} / \mathrm{m}^{2}\right)\end{array}$} & \multirow{2}{*}{$\begin{array}{c}\text { Rice } \\
\text { temperature } \\
\left({ }^{\circ} \mathrm{C}\right) \\
\end{array}$} & \multirow[b]{2}{*}{ Tempering } & \multicolumn{4}{|c|}{ Mortality of different life stages of T. castaneum (\%) } \\
\hline & & & egg & larvae & pupae & adult \\
\hline \multirow[t]{8}{*}{2125} & 50 & Yes & $84 \pm 3.6 a b$ & $82 \pm 2.5 a$ & $78 \pm 3.8 a$ & $74 \pm 5.7 a$ \\
\hline & 50 & No & $67 \pm 4.4 c$ & $68 \pm 2.5 b$ & $57 \pm 6.5 b$ & $52 \pm 9.5 b$ \\
\hline & 55 & Yes & $100 f$ & $100 \mathrm{~h}$ & $96 \pm 3.6 \mathrm{~cd}$ & $92 \pm 3.5 \mathrm{~cd}$ \\
\hline & 55 & No & $92 \pm 4.6 d$ & $93 \pm 3.2 c$ & $88 \pm 4.6 e f$ & $80 \pm 3.2 e f$ \\
\hline & 60 & Yes & $100 f$ & $100 \mathrm{~h}$ & $100 d$ & $100 \mathrm{~g}$ \\
\hline & 60 & No & $100 f$ & $100 \mathrm{~h}$ & $98 \pm 1.5 \mathrm{~cd}$ & $93 \pm 2.1 \mathrm{~cd}$ \\
\hline & 65 & Yes & $100 f$ & $100 \mathrm{~h}$ & $100 d$ & $100 \mathrm{~g}$ \\
\hline & 65 & No & $100 f$ & $100 \mathrm{~h}$ & $100 d$ & $100 \mathrm{~g}$ \\
\hline \multirow[t]{8}{*}{2780} & 50 & Yes & $91 \pm 2.1 d$ & $85 \pm 1.5 d$ & $78 \pm 4.0 \mathrm{a}$ & $72 \pm 7.6 a$ \\
\hline & 50 & No & $75 \pm 2.1 \mathrm{e}$ & $73 \pm 2.6 e$ & $64 \pm 3.2 \mathrm{~g}$ & $56 \pm 2.1 b$ \\
\hline & 55 & Yes & $100 f$ & $100 \mathrm{~h}$ & $100 d$ & $100 \mathrm{~g}$ \\
\hline & 55 & No & $98 \pm 1.5 f$ & $96 \pm 1.7 f$ & $91 \pm 1.5 \mathrm{fh}$ & $84 \pm 3.2 f$ \\
\hline & 60 & Yes & $100 f$ & $100 \mathrm{~h}$ & $100 d$ & $100 \mathrm{~g}$ \\
\hline & 60 & No & $100 f$ & $100 \mathrm{~h}$ & $100 d$ & $96 \pm 2.5 \mathrm{dg}$ \\
\hline & 65 & Yes & $100 f$ & $100 \mathrm{~h}$ & $100 d$ & $100 \mathrm{~g}$ \\
\hline & 65 & No & $100 f$ & $100 \mathrm{~h}$ & $100 d$ & $100 \mathrm{~g}$ \\
\hline \multirow[t]{8}{*}{3358} & 50 & Yes & $87 \pm 2.5 b$ & $87 \pm 3.5 d$ & $79 \pm 3.2 a$ & $75 \pm 2.3 a$ \\
\hline & 50 & No & $78 \pm 2.9 \mathrm{e}$ & $75 \pm 1.2 \mathrm{~g}$ & $67 \pm 4.0 i$ & $62 \pm 2.6 h$ \\
\hline & 55 & Yes & $100 f$ & $100 \mathrm{~h}$ & $100 d$ & $96 \pm 2.1 \mathrm{dg}$ \\
\hline & 55 & No & $100 f$ & $96 \pm 1.7 f$ & $94 \pm 2.1 \mathrm{ch}$ & $89 \pm 3.2 c$ \\
\hline & 60 & Yes & $100 f$ & $100 \mathrm{~h}$ & $100 d$ & $100 \mathrm{~g}$ \\
\hline & 60 & No & $100 f$ & $100 \mathrm{~h}$ & $98 \pm 1.5 \mathrm{~cd}$ & $97 \pm 2.6 \mathrm{dg}$ \\
\hline & 65 & Yes & $100 f$ & $100 \mathrm{~h}$ & $100 d$ & $100 \mathrm{~g}$ \\
\hline & 65 & No & $100 f$ & $100 \mathrm{~h}$ & $100 d$ & $100 \mathrm{~g}$ \\
\hline \multirow[t]{8}{*}{3974} & 50 & Yes & $92 \pm 3.6 d$ & $91 \pm 1.5 c$ & $85 \pm 3.2 e$ & $78 \pm 5.9 \mathrm{ae}$ \\
\hline & 50 & No & $83 \pm 4.6 a$ & $78 \pm 3.8 \mathrm{~g}$ & $72 \pm 3.8 j$ & $65 \pm 5.5 h$ \\
\hline & 55 & Yes & $100 f$ & $100 \mathrm{~h}$ & $100 d$ & $98 \pm 1.7 \mathrm{dg}$ \\
\hline & 55 & No & $100 f$ & $100 \mathrm{~h}$ & $96 \pm 2.3 \mathrm{~cd}$ & $93 \pm 1.5 \mathrm{~cd}$ \\
\hline & 60 & Yes & $100 f$ & $100 \mathrm{~h}$ & $100 d$ & $100 \mathrm{~g}$ \\
\hline & 60 & No & $100 f$ & $100 \mathrm{~h}$ & $100 d$ & $100 \mathrm{~g}$ \\
\hline & 65 & Yes & $100 f$ & $100 \mathrm{~h}$ & $100 d$ & $100 \mathrm{~g}$ \\
\hline & 65 & No & $100 f$ & $100 \mathrm{~h}$ & $100 \mathrm{~d}$ & $100 \mathrm{~g}$ \\
\hline
\end{tabular}

Data (mean $\pm S D$ ) in each column with different letters have significant differences $(p<0.05)$.

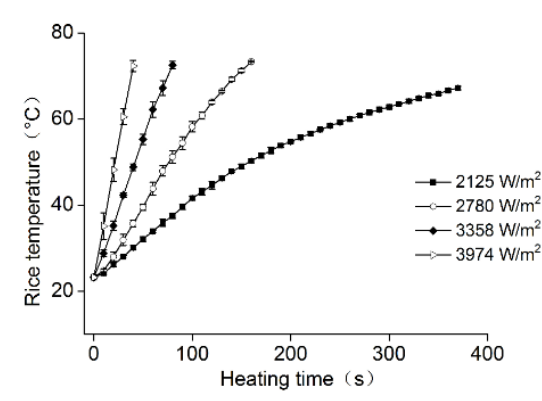

Fig. 2 Heating curve of rough rice under IR radiation intensity of $2125,2780,3358,3974 \mathrm{~W} / \mathrm{m}^{2}$.

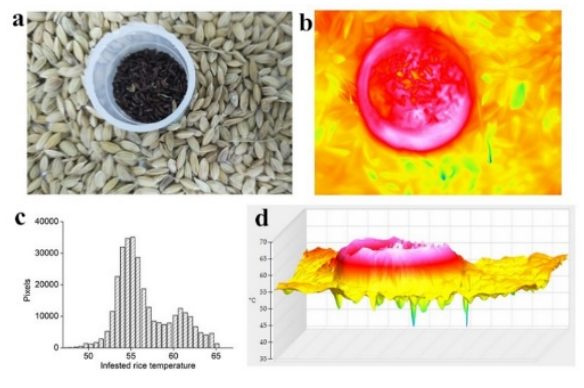

Fig. 3 Thermal (a) and visual (b) images of infested rough rice heated for $160 \mathrm{~s}$ under IR radiation intensity of $2780 \mathrm{~W} / \mathrm{m}^{2}$. The rectangle area represented rough rice, and circular area represented adult Tribolium castaneum. 
Thermal and visual images of infested rough rice heated for $160 \mathrm{~s}$ under IR radiation intensity of $2780 \mathrm{~W} / \mathrm{m} 2$ were shown in Fig. 3a and Fig. 3b. In thermal image of infested rough rice, the red part indicated that the temperature was high, and the temperature range from $50^{\circ} \mathrm{C}$ to $80^{\circ} \mathrm{C}$. The adult

T. castaneum temperature was $74.3 \pm 2.4^{\circ} \mathrm{C}$ while the rice temperature was only $71.6 \pm 3.6{ }^{\circ} \mathrm{C}$. Based on the analysis of FTIR results, when the IR radiation intensity was $2780 \mathrm{~W} / \mathrm{m}^{2}$, the maximum IR absorbance of adult $T$. castaneum was 0.3 at $1632 \mathrm{~cm}^{-1}$, and was higher than that of rough rice $(0.15$ at $1020 \mathrm{~cm}^{-1}$ ). Obviously, the IR absorption ability of adult $T$. castaneum was higher than that of rough rice. In addition, the temperature of rough rice heated using IR was uniform in Fig. 3a. The results also confirmed the previous finding that the uniformity of IR heating was higher than that of microwave heating (Kirkpatrick et al., 1972).

\section{Moisture removal}

The $M C$ of rice samples during IR heating after tempering and non-tempering with different radiation intensities were shown in Fig. 4. The $M C$ of the rough rice that heated to $50^{\circ} \mathrm{C}$ under 3358 $\mathrm{W} / \mathrm{m}^{2}$ had decreased 1.1 percentage point, which was the least moisture removal (MR) samples of all. Even though, IR heating could effectively remove the moisture in rough rice. The reason for high drying efficiency of IR was that the moisture molecules in rough rice could absorb IR easily and transfer the electromagnetic energy into intermolecular friction, which may lead to the temperature rising and moisture evaporation. Ding et al. (2015b) reported that the drying rate of studied IR heating process for rough rice was 21 and 186 times of that of hot air drying and ambient air drying, respectively.

For the rice samples dried to the same temperature under IR heating, higher moisture removal was usually achieved by those dried with lower IR intensity, which may due to the low energy efficiency of process under high IR intensity. The MR of rice was strongly positively correlated with heated rice temperature. Under the radiation intensity of $2125 \mathrm{~W} / \mathrm{m}^{2}$, the $M C$ of non-tempering samples varies $19.3 \%$ to $15.6 \%$ in the tested temperatures range from $50{ }^{\circ} \mathrm{C}$ to $65^{\circ} \mathrm{C}$. The higher rice temperature means that the more IR energy were absorbed, which could result in the molecule friction and moisture evaporation of rough rice.

It was also found that the MR after tempering treatment was higher than that without tempering. For instance, when the rice was heated to $60^{\circ} \mathrm{C}$, the MR of rice after tempering was $1.2,1.2,1.3$, and 1.5 percentage points lower that the heated rice after non-tempering, which showed that tempering treatment significantly improved the MR during cooling. The tempering process could reduce the moisture gradient in rice kernels and allow the moisture to distribute uniformly before natural cooling. For the heated rice without tempering treatment, there was a significant moisture gradient in the rough rice kernels and low MC near the rice surface, which led to less moisture removal during cooling. Therefore, tempering process is an essential step to increase the moisture removal during cooling, especially when the rice was heated to a high temperature. The results were similar to those reported by other researchers (Aquerreta et al., 2007; Dong et al., 2010; Pan et al., 2008).

Rice milling quality

The TRYs of infrared dried rough rice were shown in Fig. 5a. Compared with the untreated rough rice, the infrared drying without tempering have negative effects on the milling quality of rough rice. In contrast, the TRYs of tempered rice by using IR were higher than that of non-tempered rice. For instance, when the radiation intensity of $2780 \mathrm{~W} / \mathrm{m}^{2}$, the TRYs of rice dried by IR heating followed with tempering treatment were 2.6 percentage points higher than the untreated rough rice when the rough rice heated to $60^{\circ} \mathrm{C}$. The TRYs of the rough rice heated to $60^{\circ} \mathrm{C}$ under IR intensity of 2125 , 2780,3358 and $3974 \mathrm{~W} / \mathrm{m}^{2}$ with tempering were $69.4 \pm 0.5 \%, 70.2 \pm 0.7 \%, 69.5 \pm 0.6 \%$ and $68.6 \pm 0.9 \%$, which were higher than other groups of rough rice that heated to 50,55 and $65{ }^{\circ} \mathrm{C}$. However, the rice samples treated under $3974 \mathrm{~W} / \mathrm{m}^{2}$ with tempering had lower TRYs than the other rice samples 
heated to 50,55 and $65^{\circ} \mathrm{C}$ with tempering, which revealed that the high radiation intensity would decrease the TRY of rough rice.

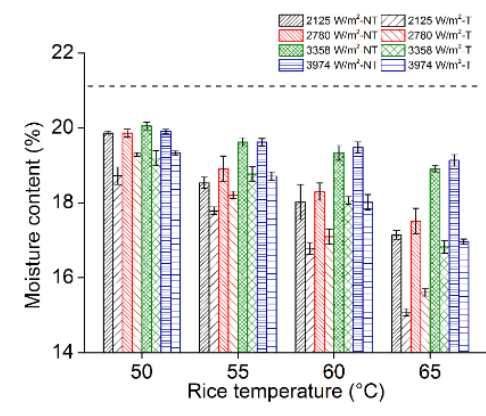

Fig. 4 Measured moisture content under IR radiation intensity of $2125,2780,3358,3974 \mathrm{~W} / \mathrm{m}^{2}$ with and without tempering for rough rice after heating to various temperatures. (T- Tempering, NTNo tempering.) In addition, the dotted line indicated the control group value (untreated samples).
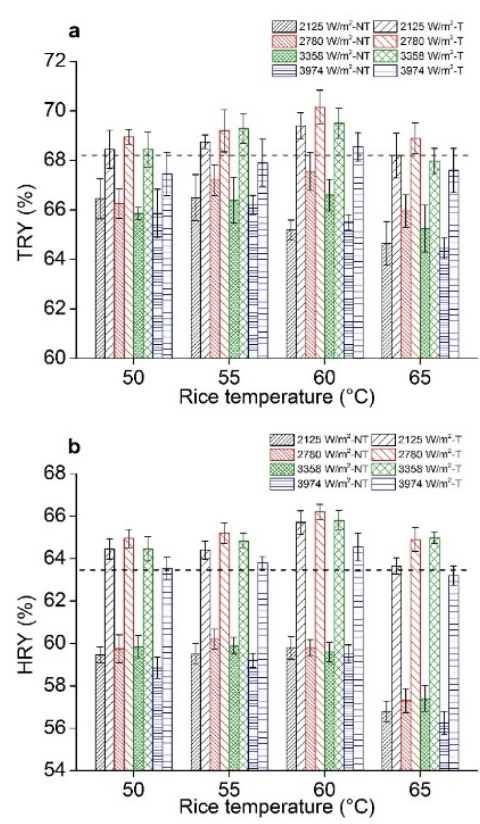

Fig. 5 Total rice yields (TRY) (a) and head rice yields (HRY) (b) of rough rice under IR radiation intensity of $2125,2780,3358,3974 \mathrm{~W} / \mathrm{m}^{2}$ for rough rice after heating to various temperatures. (T-Tempering, NTNon tempering.) In addition, the dotted line indicated the control group value (untreated samples).

Similar results were also found for the HRYs in Fig. 5b. The rough rice heated using IR with nontempering had significantly lower HRYs than the untreated rough rice. For example, the HRYs of non-tempered rice that heated to $65^{\circ} \mathrm{C}$ were 6.2 to 7.4 percentage points less than the untreated rice. However, the HRYs of the rice heated using IR with tempering were higher than untreated rice except for the rice sample dried under the IR intensity of $3974 \mathrm{~W} / \mathrm{m}^{2}$. The maximum HRY was $66.2 \pm 0.4 \%$ that was heated to $60^{\circ} \mathrm{C}$ under the intensity of $2780 \mathrm{~W} / \mathrm{m}^{2}$ with tempering.

Based on the milling quality results, the highest milling quality was achieved by IR heating to $60^{\circ} \mathrm{C}$ followed with tempering and natural cooling. Conssen (2002) reported that the glass state in rice may transfer into a rubbery state at $60^{\circ} \mathrm{C}$, and may result in a large amount of moisture removal and well maintaining of milling quality. Since the IR could penetrate the single layer of rough rice, the internal moisture in rice kernels could uniformly absorb IR as the moisture distributed close to the surface. Therefore, the temperature and moisture gradient were kept in same direction (from inside to outside) which could reduce the moisture gradient increase between internal to surface in rice kernels, and contribute to the good rice milling quality. In addition, tempering treatment plays an essential role for maintaining the rice milling quality. During cooling process, based on the glass transition hypothesis, the surface temperature and moisture of rice changed first and starch reached glass state during cooling. However, the center temperature and moisture in the rice kernel were still in rubbery state. Due to the different stage of starch in the rice kernel, stress and fissure were generated that resulting in low TRY and HRY. Therefore, tempering process is important for rough 
rice IR drying that could maintain the uniformity of temperature and moisture in the rice kernel and preserve the quality effectively.

\section{Conclusions}

IR heating was used as an alternative disinfestation method of $S$. zeamais and $T$. castaneum in rough rice. The theoretical calculation optimum temperature of IR heating was $300{ }^{\circ} \mathrm{C}$ according to the results of FTIR spectra, which corresponding to the IR intensity of $2780 \mathrm{~W} / \mathrm{m}^{2}$. After the IR radiation intensity of $2780 \mathrm{~W} / \mathrm{m}^{2}$ for $110 \mathrm{~s}$ with tempering, the mortality of S. zeamais and T. castaneum achieved $100 \%$ while the rice temperature reached $60.2^{\circ} \pm 0.5^{\circ} \mathrm{C}$. Besides, 3.97 percentage points of moisture were removed and rice milling quality were well maintained. When the rough rice was heated to $65{ }^{\circ} \mathrm{C}$, the insects could be completely killed regardless of tempering in all samples. Although the higher mortality of insect could be achieved with the increase of heated rice temperature, the higher IR heating intensity and long exposure time might reduce the rice milling quality. Therefore, the tempering treatment after IR heating is important to achieve high insect mortality and moisture removal with good rice milling quality. It can be concluded that the rough rice heated under IR of $2780 \mathrm{~W} / \mathrm{m}^{2}$ to $60{ }^{\circ} \mathrm{C}$ with tempering and cooling is a feasible processing method for rough rice disinfestation and drying.

\section{Acknowledgements}

The authors wish to thank the projects funded by National Natural Science Foundation of China (31601402), the Natural Science Foundation of the Colleges and Universities in Jiangsu Province (16KJB550004), and the Priority Academic Program Development of Jiangsu Higher Education Institutions (PAPD).

\section{References}

Alfonso-Rubí, J., Ortego, F., Castañera, P., Carbonero, P., \& Díaz, I. (2003). Transgenic expression of trypsin inhibitor CMe from barley in indica and japonica rice, confers resistance to the rice weevil Sitophilus oryzae. Transgenic Research, 12(1), 23-31.

Aquerreta, J., Iguaz, A., Arroqui, C., \& Virseda, P. (2007). Effect of high temperature intermittent drying and tempering on rough rice quality. Journal of Food Engineering, 80(2), 611-618.

ASAE (1995). Moisture measurements-ungrounded grain seeds (Moisture relationships of grains (42nd ed., Vol. S 352.2). Street Joseph, Michigan: ASAE.

Carlomagno, G. M., Astarita, T., \& Cardone, G. (2002). Convective heat transfer and infrared thermography. Journal of Applied Fluid Mechanics, 972(1), 177.

Cnossen, A. G., \& Siebenmorgen, T. J. (2002). The glass transition temperature concept in rice drying and tempering: effect on milling quality. Transactions of the Asae American Society of Agricultural Engineers, 43(6), 1661-1667.

Cogburn, R. R. (1967). Infrared Radiation Effect on Reproduction by Three Species of Stored-Product Insects. Journal of Economic Entomology, 60(2), 548-550.

Cogburn, R. R., Brower, J. H., \& Tilton, E. W. (1971). Combination of Gamma and Infrared Radiation for Control of the Angoumois Grain Moth in Wheat. Journal of Economic Entomology, 64(4), 923-925.

Ding, C., Khir, R., Pan, Z., Zhang, J., Tu, K, \& El-Mashad, H.. (2015a). Effect of infrared and conventional drying methods on physicochemical characteristics of stored white rice. Cereal Chemistry, 92(5), 441-448.

Ding, C., Khir, R., Pan, Z., Zhao, L., Tu, K., El-Mashad, H., \& Mchugh, T. H. (2015b). Improvement in Shelf Life of Rough and Brown Rice Using Infrared Radiation Heating. Food Bioprocess Technology, 8(5), 1149-1159.

Dong, R., Lu, Z., Liu, Z., Koide, S., \& Wei, C. (2010). Effect of drying and tempering on rice fissuring analysed by integrating intrakernel moisture distribution. Journal of Food Engineering, 97(2), 161-167.

Frost, S. W., Dills, L. E., \& Nicholas, J. E. (1944). The Effects of Infrared Radiation on Certain Insects. Journal of Economic Entomology, $37(2), 287-290$.

Ionel, R. P. D. (1992). Electromagnetic Radiations in Food Science. Springer Berlin Heidelberg.

Khamis, M., Subramanyam, B., Dogan, H., Flinn, P. W., Gwirtz, J. A., Carvalho, M. O., Fields, P. G., Adler, C. S., Arthur, F. H., \& Athanassiou, C. G. (2010). Effectiveness of flameless catalytic infrared radiation against life stages of three storedproduct insect species in stored wheat. Julius-Kühn-Archiv, 2010(425), 695-700.

Khir, R., Pan, Z., Salim, A., Hartsough, B. R., \& Mohamed, S. (2011). Moisture diffusivity of rough rice under infrared radiation drying. LWT-Food Science and Technology, 44(4), 1126-1132.

Kirkpatrick, R. L. (1975). Infrared Radiation for Control of Lesser Grain Borers and Rice Weevils in Bulk Wheat (Coleoptera: Bostrichidae \& Curculionidae). Journal of the Kansas Entomological Society, 48(1), 100-104.

Kirkpatrick, R. L., Brower, J. H., \& Tilton, E. W. (1972a). A Comparison of Microwave and Infrared Radiation to Control Rice Weevils (Coleoptera: Curculionidae) in Wheat. Journal of the Kansas Entomological Society, 45(4), 434-438. 
Kirkpatrick, R. L., \& Cagle, A. (1978). Controlling insects in bulk wheat with infrared radiation. Journal of the Kansas Entomological Society, 51(3), 386-393.

Kirkpatrick, R. L., \& Tilton, E. W. (1972b). Infrared radiation to control adult stored-product Coleoptera. Ga Entomol Soc J, 18(7), 1511-1522.

Lee, B. H., Choi, W. S., Lee, S. E., \& Park, B. S. (2001). Fumigant toxicity of essential oils and their constituent compounds towards the rice weevil, Sitophilus oryzae (L.). Crop Protection, 20(4), 317-320.

Matsuoka, T. (2011). Drying characteristics of rough rice by far-infrared radiation heating. Journal of the Society of Agricultural Structures, 21(2), 85-93.

Mishra, B. B., Tripathi, S. P., \& Tripathi, C. P. M. (2013). Bioactivity of Two Plant Derived Essential Oils Against the Rice Weevils Sitophilus oryzae (L.) (Coleoptera: Curculionidae). Proceedings of the National Academy of Sciences India, 83(2), 171-175.

Ogendo, J. O., Deng, A. L., Kostyukovsky, M., Ravid, U., Matasyoh, J. C., Omolo, E. O., Kariuki, S. T., Bett, P. K., Kamau, E. A. W., \& Adipala, E. (2010). Fumigant toxicity of five essential oil constituents against major stored-product insect pests of food grains. Ruforum Biennial Regional Conference on "building Capacity for Food Security in Africa", Entebbe, Uganda, 325-332.

Pan, Z., Atungulu, G. G. (2010). Infrared heating for food and agricultural processing. Boca Raton, Fla: CRC Press, 25-31.

Pan, Z., Khir, R., Godfrey, L. D., Lewis, R., Thompson, J. F., \& Salim, A. (2008). Feasibility of simultaneous rough rice drying and disinfestations by infrared radiation heating and rice milling quality. Journal of Food Engineering, 84(3), 469-479.

Pan, Z., Khir, R., Salim, A., \& Thompson, J. F. (2007). Drying characteristics and quality of rough rice under infrared radiation heating. Transactions of the ASABE, 54(1), 203-210.

Schroeder, H. W., \& Tilton, E. W. (1961). Infrared radiation for the control of immature insects in kernels of rough rice.

Tilton, E. W., Vardell, H. H., \& Jones, R. D. (1983). Infrared heating with vacuum for control of the lesser grain borer, (Rhyzopertha dominica F.) and rice weevil (Sitophilus oryzae (L.)) infesting wheat. Journal of the Georgia Entomological Society, 18(1), 6164.

Tilton, E. W., \& Schroeder, H. W. (1963). Some Effects of Infrared Irradiation on the Mortality of Immature Insects in Kernels of Rough Rice. Journal of Economic Entomology, 56(6), 727-730.

Vadivambal, R., Deji, O. F., Jayas, D. S., \& White, N. D. G. (2010). Disinfestation of stored corn using microwave energy. Agriculture \& Biology Journal of North America, 1(1), 18-26.

Yan, R., Huang, Z., Zhu, H., Johnson, J. A., \& Wang, S. (2014). Thermal death kinetics of adult Sitophilus oryzae and effects of heating rate on thermotolerance. Journal of Stored Products Research, 59, 231-236.

\title{
Effect of passing Beauveria bassiana through alkane based media on the adult mortalities of Rhyzopertha dominica and Sitophilus oryzae
}

\section{Mehmet Kubilay Er*, Cebrail Barış, Hasan Tunaz, Ali Arda Işikber}

Department of Plant Protection, Faculty of Agriculture, University of Kahramanmaras Sütçü Imam, Kahramanmaras / Turkey

*Corresponding author, e-mail:mker@ksu.edu.tr

DOI 10.5073/jka.2018.463.109

\begin{abstract}
Entomopathogenic fungi have been investigated for management of stored product pests as alternatives to chemical control. Beauveria bassiana is commonly considered and thus increasing its efficacy has also been studied. The purpose of this study is to evaluate the effect of passing two B. bassiana cultures (wild and singlespore cultures) through $\mathrm{n}$-hexadecane and $\mathrm{n}$-octocasane based media on Rhyzopertha dominica and Sitophilus oryzae adult mortalities. For each Petri plate, $2 \mathrm{ml}$ of $10 \%$ alkane was spread, let to evaporate and fungus was inoculated. After sporulation, spores for pathogenicity tests were produced by solid fermentation method on rice. Pathogenicity tests were conducted by application of $500 \mathrm{ppm}(\mathrm{w} / \mathrm{w})$ spores in wheat on 20 adults at $25 \pm 2^{\circ} \mathrm{C}, 65 \pm 5 \mathrm{r}$.h. in darkness with five replications. The efficacy of wild culture towards $R$. dominica adults was enhanced in both treatments. Mortality in 7 days increased from $35 \%$ to 55 and $69 \%$ when $n$-hexadecane and $n$ octocasane were used, respectively. Similarly, these treatments increased 14-day mortalities from $65 \%$ to 77 and $87 \%$, respectively. Treatment of single-spore culture, however, either showed no change or reduced mortality. Passing both cultures through both alkane based media did not statistically affect the activity against $S$. oryzae. This study illustrated that increasing the virulence of $B$. bassiana is possible for $R$. dominica and increase depends both on the starting fungus culture and alkane used. Starting with a wild fungus culture with a wider genetic diversity, and using n-octocasane can produce a better enhancement.
\end{abstract}

Keywords: microbial control, biological control, virulence, entomopathogen.

\section{Introduction}

Cereals are produced throughout the world as nutrition for both humans and livestock. These commodities generally require storage for at least a short time and need to be protected against 